\title{
QUASI-SINGULAR PROPOSITIONS: THE SEMANTICS OF BELIEF REPORTS
}

\author{
François Récanati and Mark Crimmins \\ I-François Récanati
}

I

$\mathrm{T}$ he Hidden Indexical Theory. When we report a belief about a particular object, we often implicitly indicate the way the believer thinks of that object. This is why two different beliefs can be reported by 'John believes that Cicero is an excellent writer' and 'John believes that Tully is an excellent writer'. One report can be true and the other false, even though 'Cicero' and 'Tully' refer to the same person. To account for this fact, it is natural to assume that the names 'Cicero' and 'Tully' are somehow associated with different 'modes of presentation' of the individual they both refer to.

What is the nature of the link between the referring expression in the 'that'-clause (in my examples, the proper name) and the mode of presentation under which the believer is understood to think of the reference? Is it semantic or pragmatic? Arguably, it is the speaker's choice of a particular referring expression (rather than the expression itself) which, in some contexts, conveys the suggestion that the believer thinks of the referent under this or that mode of presentation. To that extent the link between the proper name and the mode of presentation is 'pragmatic'. Many philosophers take this conclusion to be inconsistent with the thesis of Opacity, according to which the mode of presentation in question affects the truth-conditions of the belief report. But this is incorrect. It is possible for something which is pragmatically suggested by the use of some expression to affect the truth-conditional content of the utterance in which the expression occurs. Thus the order of the clauses in 'He took off his clothes and went to bed' (or 'They got married and had many children') pragmatically suggests that one event antedates the other, but this indication, though pragmatic, affects the truth-conditions of the utterance. That this is so is shown, 
inter alia, by the fact that if you embed the utterance and make it the first clause of an 'if-then' sentence, the temporal implication will be one of the conditions specified by the conditional's antecedent (Cohen 1971). Thus we can say: 'If they got married and had many children, her father must be happy, but if they had many children and got married, he is probably less happy'. Given that that sort of thing can happen, there is no conflict between the claim that the believer's way of thinking of an object is only pragmatically suggested by the reporter's choice of a particular referring expression and the claim that the believer's thinking of that object under that mode of presentation is one of the truth-conditions of the belief report (Opacity).

Another prima facie reason for giving up the thesis of Opacity is that it conflicts with two other theses which there are good reasons to accept: Direct Reference and Semantic Innocence. Direct Reference says that the semantic value (the content) of a term like 'Cicero' is the object it refers to. Semantic Innocence says that expressions behave in the same way-have the same sort of content - when they occur in simple sentences and when they occur in the embedded clause of a belief report. From Direct Reference, it follows that a sentence like 'Cicero is an excellent writer' expresses a singular proposition consisting of Cicero and the property of being an excellent writer. From Semantic Innocence, it follows that that singular proposition is still expressed when the sentence is embedded in the belief sentence 'John believes that Cicero is an excellent writer'. But if the embedded sentence expresses that singular proposition, substituting 'Tully' for 'Cicero' should make no difference, since 'Tully' and 'Cicero' are coreferential; there should be no opacity. Impressed by this argument, some philosophers have claimed that the mode of presentation does not find its way into ' what is literally said' by the belief report but remains a peripheral adjunct at the 'implicature' level (Salmon 1986).

But this argument against Opacity is not compelling either. (This is fortunate, for the 'implicature' analysis raises problems of its own-see Récanati 1993, chapter 17.) As Crimmins and Perry have shown, it is possible to reconcile the three conflicting theses: Opacity, Direct Reference and Semantic Innocence. One can do this by adopting an analysis of belief reports which Schiffer offered almost twenty years ago and which Crimmins and Perry redis- 
covered and elaborated (Schiffer 1977; Crimmins and Perry 1989; Crimmins 1992). According to this analysis, which Schiffer calls the 'Hidden Indexical Theory', a belief report like 'John believes that Cicero is an excellent writer' does not state a dyadic relation between John and the singular proposition $<$ Cicero, the property of being an excellent writer> but rather a triadic relation between John, that singular proposition, and a mode of presentation (a way of thinking of the constituents of the proposition, including Cicero). Substituting 'Tully' for 'Cicero' does not affect the singular proposition which is the truth-conditional content of the ascribed belief, but it affects the notion of Cicero implicitly ascribed to the believer. Using the term 'Tully' in the report may suggest that the believer thinks of Cicero as 'Tully'. Because the substitution does not affect the singular proposition expressed by the embedded sentence (i.e. the second argument of the belief-relation), Direct Reference and Semantic Innocence are preserved: whether embedded or unembedded, the sentence 'Cicero is an excellent writer' always expresses the same proposition (Semantic Innocence), and that proposition is singular (Direct Reference). The fact that the proposition is singular entails that substituting 'Tully' for 'Cicero' does not change the proposition which the sentence expresses. The Hidden Indexical Theory accepts this consequence of Direct Reference; it is nevertheless able to accept also the thesis of Opacity, for the substitution affects the overall truth-conditions of the belief report (by affecting the third argument of the belief relation) even if it does not affect the truth-conditions of the embedded sentence. It affects the overall truth-conditions of the belief report by affecting the third argument of the belief relation.

The theory thus sketched rests on the idea that belief reports are not what they seem to be; they seem to state a dyadic relation between the believer (referred to by the subject term) and a content (expressed by the embedded sentence), but in fact they state a triadic relation an argument of which is superficially 'hidden'. The content of the belief report involves not only the believer, the belief relation and the belief content, but also a mode of presentation under which the believer believes that content. Contrary to the other constituents, which are all 'articulated' because they correspond to something in the sentence-the believer to the subject term, the belief relation to the main verb, and the belief content to the 
'that'-clause-the mode of presentation is 'unarticulated'; it is implicitly referred to, as is the place where it is raining when someone simply says 'It's raining'. The unarticulated mode of presentation may nevertheless be sensitive to which words are used in expressing the content of the belief, for the words which are used are part of the context, and the implicit reference to a mode of presentation is highly context-sensitive.

Like Stephen Schiffer (1992), I think a more straightforward theory-a theory which would avoid positing a discrepancy between the grammar of belief reports and their logical formwould be prima facie preferable, if at all possible. But is it possible? Can we preserve dyadicness in the semantic analysis of belief reports without giving up one of the three theses-Opacity, Direct Reference or Semantic Innocence? This is the question I will address in this paper. The answer I will provide has two parts. I will first argue that, by appealing to 'quasi-singular propositions', we can reconcile Opacity, Direct Reference and Semantic Innocence without positing a logical form distinct from the superficial form of belief reports-without giving up dyadicness. This does not entirely settle the issue, however. At the end of the paper, I will show that there is an independent reason for going triadic, even if we opt for the quasi-singular analysis.

An alternative analysis of belief reports. Like utterances, beliefs have a representational content, by virtue of which they are evaluable as true or false. Thus the belief that Cicero is an excellent writer has a truth-conditional content involving Cicero and the property of being an excellent writer. The objects and properties which occur as constituents in the truth-conditional content of a belief can be represented in different ways, however. Cicero's belief that he himself is an excellent writer has the same truth-conditional content as John's belief that Cicero is an excellent writer, but Cicero's notion of himself is very different from John's notion of Cicero. Or imagine someone who does not know that Cicero is Tully, and who has, or thinks she has, some beliefs about Cicero and some beliefs about Tully. For example, she believes that Cicero was a Roman orator, and she also believes that Tully was a Roman orator. 
Both types of belief are in fact about Cicero, yet the believer does not know this; as a result she may give up one belief while retaining the other. She now believes that Cicero was Roman but not Tully. This is possible because the two beliefs, while about Cicero, involve different modes of presentation (different 'notions') of him. That such a distinction must be drawn between the object thought about and the way it is thought about is well-known. It follows that beliefs can be classified in two ways (Perry 1993): either by their truth-conditional content (Cicero, when he thinks 'I am an excellent writer', thinks the same thing which we believe when we believe 'Cicero is an excellent writer' or 'Tully is an excellent writer'), or by the modes of presentation or notions involved (Cicero and John both think the same thing when they think 'I am an excellent writer'). What I will refer to as 'the fine-grained classification of beliefs' adverts to both dimensions at once.

Singular propositions are useful for classifying beliefs by their truth-conditional contents: Cicero's belief that he is an excellent writer and John's belief that Cicero is an excellent writer have the same truth-conditional content, representable as the singular proposition consisting of Cicero and the property of being an excellent writer. In the same way, I suggest, "quasi-singular propositions' (Schiffer 1978; Récanati 1993) provide a useful tool for classifying beliefs in a fine-grained manner. Quasi-singular propositions are like singular propositions, except that to the normal constituents of a singular proposition are associated modes of presentation (or, rather, types of mode of presentation). Thus the constituents of a quasi-singular proposition are ordered pairs involving the normal constituent of the corresponding singular proposition and a mode of presentation of that constituent. ${ }^{1} \mathrm{~A}$ crucial property of the modes of presentation in question is their truth-conditional irrelevance (Récanati 1993). A quasi-singular proposition to the effect that some object $a$ is $\mathrm{G}$ includes a mode of presentation $\mathbf{m}$ of $a$, but its truth-condition is genuinely singular: the proposition is true iff the object, $a$, is $\mathrm{G}$.

1 Following my usual policy, I will simplify matters by ignoring the modes of presentation of properties and relations. 
Singular proposition: <Cicero, the property of being an excellent writer>

Quasi-singular proposition: $<<$ Cicero, $\mathbf{m}>$, the property of being an excellent writer>

Quasi-singular propositions capture the two dimensions along which we classify beliefs. If we say that someone, say John, believes a certain quasi-singular proposition, this means that he believes a certain singular proposition under a certain mode of presentation. The two manners of expression are equivalent, but that involving quasi-singular propositions is faithful to the superficial form of belief reports in natural language. It is therefore very tempting to construe the embedded sentence in a belief report as expressing a quasi-singular proposition, to which the 'that'-clause refers. Substituting 'Tully' for 'Cicero' preserves the truth-conditional content of the embedded sentence (which content can be represented as a singular proposition) but affects the quasi-singular proposition by changing the mode of presentation which, together with Cicero, constitutes the first constituent of the quasi-singular proposition:

John believes that Cicero is an excellent writer =

B (John, <<Cicero, 'Cicero'>, the property of being an excellent writer $>$ )

John believes that Tully is an excellent writer $=$

B (John, $<<$ Cicero, 'Tully' $>$, the property of being an excellent writer>)

Cicero believes that he himself is an excellent writer $=$

B (Cicero, $<<$ Cicero, self $>$, the property of being an excellent writer $>$ )

Why not, then, opt for this straightforward analysis of belief reports? Because, arguably, such an analysis does not permit us to preserve Direct Reference and Semantic Innocence. By virtue of the latter, if the embedded sentence in a belief report expresses a quasi-singular proposition, the same sentence should also express a quasi-singular proposition when it occurs in isolation; and this seems to conflict with Direct Reference, according to which a sentence like 'Cicero is an excellent writer' expresses a singular 
proposition consisting of Cicero and the property of being an excellent writer.

But the suggested analysis in terms of quasi-singular propositions seems to me basically correct, and I want to defend it. I will argue, first, that sentences like 'Cicero is an excellent writer', involving a directly referential expression in a predicative frame, do indeed express quasi-singular propositions when uttered in isolation. The quasi-singular analysis of belief reports is therefore consistent with Semantic Innocence. (This claim will be qualified in section V.) As for Direct Reference, I will argue that adopting the quasi-singular analysis does not lead us to give it up. As I interpret it the principle of Direct Reference is consistent with the view that a sentence like 'Cicero is an excellent writer' expresses a quasi-singular proposition involving a mode of presentation of Cicero.

\section{III}

Semantic content. Before going further we must clarify the notion of what an utterance expresses. I think we need a distinction between 'the proposition expressed by an utterance' in the narrow, Kaplanian sense, and the utterance's complete 'semantic content' (what it expresses in a broader sense).

Let us first contrast the proposition expressed in the narrow sense with the 'thought' in the mind of the speaker (or the hearer). When we think of objects we cannot but think of them under modes of presentation. So called 'singular' thoughts--thoughts about particular objects, e.g. the thought that Cicero is an excellent writer -have to include such modes of presentation, hence they cannot be 'singular' in the sense in which Kaplan talks of singular propositions, containing an object and what is said about it, but at best 'quasi-singular'. In contrast, the (Kaplanian) proposition expressed by an utterance is individuated on a truth-conditional basis and does not include the (truth-conditionally irrelevant) modes of presentation which are part of the accompanying thoughts. The same proposition is thus expressed whether Cicero says ' $\mathrm{He}$ is an excellent writer', pointing to his image in the mirror, or 'I am an excellent writer', despite the considerable difference between the two modes of presentation. 
The utterance's complete semantic content-what the utterance expresses, in the broad sense-is something intermediate between the Kaplanian proposition and the thought in the mind of the speaker or the hearer. It goes beyond mere truth-conditional content and includes cognitively relevant but truth-conditionally irrelevant modes of presentation. Yet it need not include any old mode of presentation that actually occurs in the speaker's thought. Stephen Schiffer once characterized the thought 'expressed' by an utterance (as opposed to the proposition 'asserted') as 'the complete content of the proximal thought which plays a pivotal role in the causal chain eventuating in the utterance' (Schiffer 1981: 57). This is too broad and corresponds to what I simply call the thought in the mind of the speaker. What is expressed, in the sense I am trying to characterize, is more restrictive. What is expressed has to be meant -it is part of the utterance's semantic content.

A necessary condition for something's being expressed and part of semantic content might be the following. A thought is not expressed if it is not communicated, that is, if the hearer does not come to entertain the thought in question as a result of her understanding the utterance. So in order to be expressed a thought has to be shared by the participants in the communication process. It follows that if the speaker thinks of the reference in a certain way, and the hearer in another way, then the mode of presentation which occurs in the speaker's thought is not expressed-it is not part of the semantic content of the utterance.

The shareability condition may seem too strong, for the following reason. Suppose Cicero says 'I am an excellent writer'. $\mathrm{He}$ does not merely express the proposition that Cicero is an excellent writer-that very singular proposition which would also be expressed if someone had said, pointing to Cicero, 'He is an excellent writer'. A certain mode of presentation is also expressed by the first-person ' $I$ '. Which one? The first answer that comes to mind is that the first person expresses a first person mode of presentation-Cicero's notion of himself. But this mode of presentation, as Frege noticed, is not shareable. Cicero certainly thinks of himself in the first person way, he certainly thinks the thought that he himself is an excellent writer when he utters 'I am an excellent writer', but the hearer does not come to entertain a first-person thought as a result of understanding the utterance. The 
hearer entertains the thought that Cicero is an excellent writer, not the thought that 'he himself' is an excellent writer.

Still, I think the shareability condition is OK. What is expressed by the first person ' $I$ ' is not something as specific as Cicero's unshareable notion of himself, but rather a type of mode of presentation of which both Cicero's notion of himself and the hearer's third-person notion of Cicero are particular instances. Cicero's notion of himself and the hearer's third-person notion of Cicero can be seen as 'dossiers of information'. When someone thinks of an object through some dossier of information, the thought is about the object from which the information (or misinformation) derives, and is true if and only if the object in question possesses whatever property the thought ascribes to the object thought about. In the case at hand (Cicero's utterance of 'I am an excellent writer' addressed to, say, his friend Septimus), the speaker and the hearer both think of the reference through some dossier which contains the information that the referent (the object the dossier is about) is uttering this utterance of 'I am an excellent writer'. This common element is what defines the type of truth-conditionally irrelevant mode of presentation which the utterance expresses (Récanati forthcoming). The type of mode of presentation in question is instantiated both by the speaker's thought and by the hearer's thought; the shareability constraint is therefore satisfied.

Far from being too strong, the shareability constraint is not strong enough. For even if the addressee does think of the referent in the same way as the speaker, even if she comes to entertain the same thought as a result of the communication process, still this may be a contingent fact in the sense that her understanding the speaker's utterance does not require her to do so. So the condition to be satisfied for inclusion into semantic content seems to me to be approximately this: something is part of the semantic content of an utterance only if it is part of the representation which someone must form in order to 'understand' the utterance correctly. ${ }^{2}$ In the next section I will show that truth-conditionally irrelevant modes of

2 This condition, stated quite explicitly by Evans (Evans 1982:92, 171, etc.), also follows from Grice's theory of meaning (Grice 1989). 
presentation satisfy this constraint and pass the test for inclusion into semantic content.

\section{IV}

Quasi-singular propositions and simple sentences. Consider the following example, due to Brian Loar:

Suppose that Smith and Jones are unaware that the man being interviewed on television is someone they see on the train every morning and about whom, in that latter role, they have just been talking. Smith says 'He is a stockbroker', intending to refer to the man on television; Jones takes Smith to be referring to the man on the train. Now Jones, as it happens, has correctly identified Smith's referent, since the man on television is the man on the train; but he has failed to understand Smith's utterance. It would seem that, as Frege held, some 'manner of presentation' of the referent is, even on referential uses, essential to what is being communicated. (Loar 1976: 357)

As Loar points out, merely identifying the reference is not sufficient for understanding, in a case like this; the reference must be thought of under a particular type of mode of presentation-this is required for understanding.

Loar's example is not a mere curiosity; it sheds light on the semantic content of all utterances including genuine singular terms. For any such utterance, I think it is possible to imagine a kind of misunderstanding similar to that involved in Loar's example, i.e. a situation in which the hearer would identify the proper referent in an improper way (under the wrong mode of presentation). The fact that such misunderstanding is always possible entails that there always is a mode of presentation as part of semantic content.

The mode of presentation which is part of semantic content typically depends on the speaker's communicative intentions. In Loar's example, the speaker intends the hearer to identify the man on television as the man he is talking about; there is misunderstanding because the hearer does not recognize the speaker's intention: he mistakenly believes the speaker intends him to identify the man on the train. Even if we leave the speaker's intentions aside, however, it is clear that we must allow modes of presentation into semantic content. For the words which are used to refer always present the referent in a certain way; this 'linguistic' mode of 
presentation (Kaplan's 'character') is truth-conditionally irrelevant but it constrains the way the hearer is to think of the reference. Take the word 'I', which conventionally refers to the speaker. The reference rule governing the word falls short of actually determining the mode of presentation under which the reference is thought of, but it constrains it. Thus the speaker who says ' $I$ ' and the hearer who understands him think of the reference in very different ways--the speaker thinks of himself in the first person way, while the hearer thinks of the speaker in a third person, demonstrative way ('that guy'). But the notions which occur in their respective thoughts - their respective 'files' about the speaker-both include the property of being the utterer. The speaker is conscious of being the utterer (his dossier about himself includes the property of being currently speaking) and the hearer's dossier about the speaker also contains that piece of information. A type of mode of presentation is therefore expressed by the utterance by virtue merely of its linguistic meaning - and narrowed down by virtue of the speaker's recognizable communicative intentions.

At whatever level of specificity and contextual 'incrementation' we consider the mode of presentation, one thing is clear: the semantic content of the utterance is not merely a singular proposition - it is a quasi-singular proposition including a (type of) mode of presentation. There being such a mode of presentation does not really conflict with Direct Reference, for the mode of presentation in question is truth-conditionally irrelevant. This means that only the reference is relevant when it comes to determining the truthconditions of the utterance. Now Direct Reference says that the semantic value of a directly referential expression is its reference, and the semantic value of the corresponding sentence a singular proposition. What is meant by 'semantic value' here? Does it mean semantic content in the sense of what must be grasped for there to be understanding, or merely truth-conditional content? On the moderate interpretation I put forward in my book (Récanati 1993), Direct Reference only says that the truth-conditional content of e.g. a proper name is its reference. This does not necessarily exhaust the semantic content of the term. A truth-conditionally irrelevant mode of presentation may (indeed must) also be considered as part of semantic content. 
Kaplan himself acknowledged the phenomenon of truthconditional irrelevance when he decided to split the complete content of an utterance in two: (truth-conditionally irrelevant) 'character' and (truth-conditional) 'content'. Direct Reference as a thesis about the Kaplanian 'content' of utterances including directly referential terms clearly is a thesis about truth-conditional content. I think that, by explicitly using the notion of 'truth-conditional irrelevance', we achieve the same effect as Kaplan's two-tiered theory within a single layer of content-simply by stipulating the truth-conditional irrelevance of some aspect of content. In quasisingular propositions, the constituents are ordered pairs whose second constituents (the modes of presentation) are truthconditionally irrelevant. Because modes of presentation are truth-conditionally irrelevant, the claim that utterances like 'Cicero is an excellent writer' express quasi-singular propositions is compatible with Direct Reference, i.e. with the claim that singular terms like 'Cicero' contribute their reference (and only their reference) to the truth-conditional content of the utterances where they occur.

\section{V}

Semantic Innocence and the distinction between 'exercised' and 'ascribed' modes of presentation. Now that the basic framework is set, we must consider a complication. I have defended the view that a singular belief report, on its 'opaque' interpretation, asserts a dyadic relation between the believer and a quasi-singular proposition. The quasi-singular proposition is what the embedded sentence expresses, in the context of the belief report. This analysis, I claimed, is consistent with Semantic Innocence, for a sentence like 'Cicero is an excellent writer' also expresses a quasi-singular proposition when it occurs unembedded. But there is a tension between this claim and Quine's observation that some belief reports are 'de re'. Quine calls a belief report 'de re' when no mode of presentation is ascribed to the believer. When, pointing to Ortcutt on the beach, I say 'Ralph believes that he is a spy', the belief report is 'de re': I say of Ortcutt that Ralph believes him to be a spy, without indicating how Ortcutt is represented in Ralph's thought. In such a case it seems that the content ascribed to the believer is 
singular rather than quasi-singular. But if the ascribed content is what the embedded sentence would express if uttered in isolation (Semantic Innocence), and if, as I said above, an utterance like 'He is a spy', unembedded, expresses a quasi-singular proposition, the ascribed content ought to be quasi-singular rather than singular; there should be no 'de re' belief report. The very existence of such reports therefore raises a problem for my account.

There is another, related observation. When the belief report is not 'de re', i.e. when some mode of presentation is ascribed, the latter does not necessarily conform to the type linguistically expressed. This is a very common phenomenon. Consider Mark Richard's famous 'phone booth' example (Richard 1983: 439). The speaker says to Wanda, to whom he is talking on the phone, 'The man watching you believes that you are in danger'. The man he is referring to is supposed to be seeing Wanda in the phone booth about to be crushed by a caterpillar. Now 'you' expresses a type of mode of presentation involving the property of being the addressee. But in the belief the speaker ascribes to the watching man, Wanda is not represented as 'the addressee' (the watching man is not participating in the speech episode in which Wanda fulfils the function of addressee); rather she is presented as 'that woman I see in the phone booth', or something like that (Crimmins and Perry 1989: 708).

Both observations point to the necessity of a distinction between 'exercised' and 'ascribed' modes of presentation (Récanati 1993: 389 seq.). In Richard's example, the 'addressee' mode of presentation, though not ascribed to the believer, is actually 'exercised' by the speaker (the utterer of the belief report) in communicating with the hearer about the reference (the hearer herself). Qua participants in the current speech episode, they both identify the reference of the speaker's 'you' as 'the addressee' (i.e. Wanda), even if they do not ascribe that way of identifying the reference to the believer. The distinction between the two modes of presentation (exercised and ascribed) accounts for the cases in which the ascribed mode of presentation is not of the type linguistically expressed by the referring expression: it is the exercised mode of presentation which must conform to the type linguistically expressed-the ascribed mode of presentation may, but need not, do so.

Thanks to the distinction between exercised and ascribed modes of presentation, the claim that utterances with referential terms 
always express quasi-singular propositions including a mode of presentation of the reference of the term turns out to be compatible with the existence of 'de re' belief reports; for even if no mode of presentation of the object the belief is about is ascribed to the believer, there always is a mode of presentation of that object which is exercised by the speaker in communicating with the hearer. When the speaker says, pointing to Ortcutt on the beach, 'Ralph believes he is a spy', a certain mode of presentation of Ortcutt mutually available to the speaker and the hearer (through their vision of Ortcutt on the beach, etc.) is exploited for communicational purposes even if it is not ascribed to the believer.

The distinction between exercised and ascribed modes of presentation raises a problem from the point of view of Semantic Innocence, however. If what I have said is correct, 'Cicero is an excellent writer' behaves fairly differently when uttered in isolation and when uttered as part of a belief report. Unembedded, 'Cicero is an excellent writer' expresses a straightforward quasi-singular proposition; the mode of presentation which occurs in the quasisingular proposition can only be that which the speaker 'exercises' in communicating with the hearer. But when the sentence is prefixed with 'John believes that', John's point of view is brought into the picture; the mode of presentation under which John thinks of Cicero becomes relevant. In other words, when the sentence is uttered as part of a belief report, its content is enriched because, in some cases at least, the believer's mode of presentation is expressed along with the speaker's. This seems to run counter to Semantic Innocence. The latter says that the content of the sentence is the same whether uttered in isolation or as part of a belief report; but I have just conceded that in the belief report the complement sentence is semantically richer than it is in isolation.

The conflict is more apparent than real, however. The first thing to notice is that besides 'John' and 'Cicero', there is another referring expression in the sentence, namely the 'that'-clause. 'That'-clauses arguably denote different types of object (e.g. facts or propositions) in different embedding frames-this is one of the aspects under which they are context-sensitive. In contexts of belief ascription 'that'-clauses typically refer to belief contents. Now what are belief contents? They are quasi-singular propositions including the mode of presentation under which the believer thinks of the 
reference. In the context of an ascription of belief to John, the reference of the 'that'-clause is naturally understood to be a quasisingular proposition including John's mode of presentation of the object the belief is about (e.g. Cicero). In this way the semantic enrichment which affects the sentence once embedded under 'John believes that' (the provision of John's mode of presentation) is explained away as a by-product of the process of providing a reference for the 'that'-clause in a context of belief reporting.

Is this mechanism compatible with Semantic Innocence? I think it is. Semantic Innocence comes in two varieties: there is a general thesis of Semantic Innocence and a special thesis. The general thesis says that words behave in the normal way when they occur in contexts of attitude ascription. The special thesis-'Sentential Innocence', as we might call it-is much more specific; it says that the content of the sentence once embedded is necessarily the same as that of the sentence unembedded. This thesis does not make room for context-sensitivity and can hardly be accepted as it stands; but we can modify it and say that the sentence expresses the same content, whether it is embedded or unembedded, provided the context remains constant. That such a qualification is required I take to be obvious: If we change the context, this may affect e.g. the reference of an indexical expression in the sentence, hence the proposition expressed by the sentence; this would clearly not constitute a counter-example to Semantic Innocence properly understood, for the change in expressed content would be traceable to a change of context. Now the mechanism I have described is compatible with this qualified version of Sentential Innocence, for the semantic difference we have spotted between the sentence when it occurs in isolation and the same sentence embedded in a belief report (viz. the contextual provision of the ascribed mode of presentation) can be traced back to the fact that prefixing the sentence with 'John believes that' somehow changes the context: the context becomes a context of belief ascription, and this affects the reference of the 'that'-clause (the reference of the 'that'-clause in a context of belief ascription is likely to be a belief content, i.e. a quasi-singular proposition including a mode of presentation characterizing the believer's point of view).

Be that as it may, my analysis of belief reports is in perfect harmony with the general thesis of Semantic Innocence. The 
semantic enrichment due to the contextual provision of the ascribed mode of presentation does not result from a shift in the semantic rules which respectively apply to embedded and unembedded sentences (in the manner of Frege), but from the normal functioning of the normal rules of interpretation. The words used in the belief sentence behave normally and have the same sort of content they have in any other context. In particular the name 'Cicero' in 'John believes that Cicero is an excellent writer' does what it normally does: it refers to Cicero and expresses a certain mode of presentation of him (that 'exercised' by the speaker in communicating with the hearer). What is special about belief reports is that a further referring expression, viz. the 'that'-clause, comes into play. In belief reports the 'that'-clause refers to a belief content and the latter includes a mode of presentation under which the believer (not the speaker or the hearer) thinks of the object of belief. Semantic Innocence is preserved because the ascribed mode of presentation is not part of the interpretation of the name in the belief report; it is part of the interpretation of the 'that'-clause (see Récanati 1993: 396-7 on the analogy with 'Giorgione'-sentences).

\section{VI}

Quine's triadic analysis. So far I have argued in favour of a dyadic analysis of belief reports. On this analysis 'John believes that Cicero is an excellent writer' (opaquely understood) is to be represented as

(1) B (John, $<<$ Cicero, $\mathbf{m}>$, the property of being an excellent writer $>$ ) The problem with this representation is that it makes room for only one mode of presentation of Cicero. Hence the distinction between exercised and ascribed modes of presentation cannot be represented. By going triadic, in the manner of Quine (1956), we can overcome this difficulty.

Quine suggests that de re belief reports ascribe triadic relations between the believer, the referent, and the property believed of the referent. Instead of

(2) B (John, <Cicero, the property of being an excellent writer $>$ )

we have something like

(3) B (John, Cicero, $<x$, the property of being an excellent writer $>$ ) 
where ' $<x$, the property of being an excellent writer $>$ ' is a schematic singular proposition with a free variable instead of the objectual component.

Quine mistakenly thought this triadic analysis worked only for belief reports in which no mode of presentation is ascribed to the believer. However, Brian Loar (1972) has convincingly shown that Quine's analysis fits all the cases in which the reported belief involves a particular individual, whether or not a mode of presentation of that individual is ascribed to the believer. There are two sorts of 'relational' belief reports amenable to Quine's analysis: in one type of case some mode of presentation of the individual the belief is about is ascribed to the believer, in the other type of case no mode of presentation is ascribed. Quine considered only the latter type of case, corresponding to formula (3) above. The other type of relational belief, in which a mode of presentation is ascribed to the believer, can be represented in a very similar fashion, using a schematic quasi-singular proposition instead of a schematic singular proposition:

(4) B (John, Cicero, $<<x$, m>, the property of being an excellent writer>)

(4) is a triadic rephrasal of (1), as (3) is a triadic rephrasal of (2).

The main advantage of the triadic rephrasal is that it enables us to represent the distinction between exercised and ascribed modes of presentation. The mode of presentation which occurs in the schematic quasi-singular proposition in (4) is the mode of presentation of Cicero which is ascribed to the believer. But the other mode of presentation of Cicero-that which is exercised by the speaker-is easy to represent:

(5) B (John, $<$ Cicero, $\mathbf{m}_{\mathbf{j}}>,<<x, \mathbf{m}_{\mathrm{k}}>$, the property of being an excellent writer $>$ )

In this formula we have two modes of presentation of Cicero, corresponding to the distinction between exercised and ascribed modes of presentation. The first mode of presentation, $\mathbf{m}_{\mathrm{j}}$, is tied to the speaker's act of reference to the object the belief is about; the second one, $\mathbf{m}_{\mathrm{k}}$, is an aspect of the ascribed content. The two modes of presentation can, but need not, be identified: only in some contexts will it be the case that $\mathbf{m}_{\mathrm{j}}=\mathbf{m}_{\mathbf{k}}$. In other contexts $\mathbf{m}_{\mathrm{j}}$ may 
be different from $\mathbf{m}_{\mathrm{k}}$, and in still other contexts $\mathbf{m}_{\mathrm{k}}$ is vacuous-no mode of presentation is ascribed ('de re' belief reports).

Note that, strictly speaking, the representation I have just given is incomplete because a mode of presentation must be associated with John (the believer) a well as with Cicero (the object of belief), since both are referred to by the speaker. The complete representation is:

(6) B ( $<$ John, $\mathbf{m}_{\mathrm{i}}>,<$ Cicero, $\mathbf{m}_{\mathrm{j}}>,<<x, \mathbf{m}_{\mathrm{k}}>$, the property of being an excellent writer $>$ )

The belief report, like any sentence containing referential expressions such as 'John' or 'Cicero', expresses a quasi-singular proposition including modes of presentation of the referents, John and Cicero. Besides John and Cicero, the belief relation has a third argument: what is believed about Cicero. This last argument is an 'unsaturated' content, as is indicated by the presence of a variable in the representation of the third argument. The variable is a placeholder indicating a slot to be filled by the second argument (the object the belief is about). Adjoining a mode of presentation to the variable means that the content ascribed to the believer (John) about the object of belief (Cicero) includes not only what John is said to believe about Cicero but also how he thinks of Cicero.

I conclude that a triadic analysis of belief reports, though not necessary for reconciling Opacity, Direct Reference and Semantic Innocence, may well be indispensable if we want to be able to represent the central distinction between exercised and ascribed modes of presentation. ${ }^{3}$

\section{REFERENCES}

Cohen, L.J., 1971: Some Remarks on Grice's Views about the Logical Particles of Natural Language. In Y. Bar-Hillel (ed.), Pragmatics of Natural Language, Dordrecht: Reidel, 50-68.

Crimmins, M. and J. Perry, 1989: The Prince and the Phone Booth. Journal of Philosophy 86: 685-711.

Crimmins, M., 1992: Talk About Beliefs. Cambridge, Mass: MIT Press/Bradford Books.

3 I am indebted to Kent Bach, Eros Corazza, Frank Döring, Graeme Forbes, Mike Harnish, Paul Horwich, Pierre Jacob, Stephen Neale, John Perry, Stephen Schiffer, Ken Taylor, and Richard Vallée for helpful comments or suggestions. 
Evans, G., 1982: The Varieties of Reference (ed. J. McDowell). Oxford: Clarendon Press.

Grice, P., 1989: Studies in the Way of Words. Cambridge, Mass.: Harvard University Press.

Loar, B., 1972: Reference and Propositional Attitudes. Philosophical Review 81: 43-62.

Loar, B., 1976: The Semantics of Singular Terms. Philosophical Studies 30: 353-77.

Perry, J., 1993: The Problem of the Essential Indexical and Other Essays. New York: Oxford University Press.

Quine, W.v.O., 1956: Quantifiers and Propositional Attitudes. Journal of Philosophy 53: 177-87.

Récanati, F., 1993: Direct Reference. Oxford: Basil Blackwell.

Récanati, F, forthcoming: The Communication of First-Person Thoughts. In P. Kotatko and J. Biro (eds.), Sense and Reference One Hundred Years Later. Dordrecht: Kluwer, 1995.

Richard, M., 1983: Direct Reference and Ascriptions of Belief. Journal of Philosophical Logic 12: 425-52.

Salmon, N., 1986: Frege's Puzzle. Cambridge, Mass: MIT Press/Bradford Books. Schiffer, S., 1977: Naming and Knowing. Midwest Studies in Philosophy 2: 28-41.

Schiffer, S., 1978: The Basis of Reference. Erkenntnis 13: 171-206.

Schiffer, S., 1981: Indexicals and the Theory of Reference. Synthese 49: 43-100.

Schiffer, S., 1992: Belief Ascription. Journal of Philosophy 89: 499-521. 


\title{
QUASI-SINGULAR PROPOSITIONS: THE SEMANTICS OF BELIEF REPORTS
}

\author{
François Récanati and Mark Crimmins
}

\section{II-Mark Crimmins}

Rrançois Récanati aims to analyze belief ascriptions, which are
statements such as the following:

(1) Tom believes that Cicero was louder than Tully.

(2) Tom believes that Tully was louder than Cicero.

On his analysis, to a first approximation, these statements claim the holding of 'the belief relation' between a person and a quasi- singular proposition. The nature of such a proposition is perhaps best explained by way of the simpler idea of a singular proposition. The singular proposition that is expressed equally by the that-clauses in ascriptions (1) and (2) often is represented as follows (simplifying in various ways):

(3) $<$ Louder, Cicero, Cicero $>$.

This singular proposition has as constituents the relation Louder and the individual Cicero (twice over). For the proposition to be true is for the constituent individuals to stand in the constituent relation (in this case, for Cicero to be louder than Cicero). There may be more complicated singular propositional forms besides this simple relation-arguments form. Notice that every constituent of a singular proposition is truth-conditionally relevant, in that for the proposition to be true is for a fact to hold that involves each constituent. In contrast, the quasi-singular propositions ascribed as objects of belief to Tom in the ascriptions (1) and (2) might be represented as follows (I adopt a somewhat different graphical convention from Récanati, for a reason that will become clear):
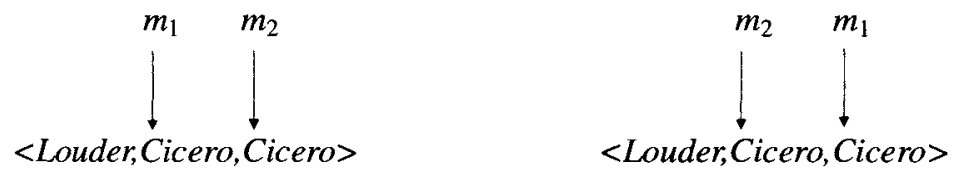
These abstract, structured entities have the same conditions of truth as the simpler singular proposition (3). The difference is that they contain additional elements that are truth-conditionally irrelevant, namely, certain modes of presentation that are, as Récanati puts it, 'associated' with some of the truth-conditionally relevant elements. (I will ignore throughout the distinction between modes and types of mode of presentation.) What these associated elements affect is not what it is for the proposition containing them to be true, but only what it takes for the proposition to be an object of thought: those modes of presentation must be employed by the thinker in representing the associated truth-conditionally relevant elements. But while the modes of presentation in a quasi-singular proposition $p$ are irrelevant to the truth of $p$ itself, they are very relevant to the truth of an ascription of $p$ to a believer. The conditions of truth for the belief ascriptions (1) and (2), for instance, differ precisely in which of these two truth-conditionally identical quasisingular propositions Tom is ascribed as an object of belief.

Récanati is fond of the dyadic aspect of this analysis, which I will call simply the dyadic analysis, because the surface grammar of belief ascriptions seems plainly dyadic. But he thinks that the dyadic analysis will not do, because there must be room for two modes of presentation to be associated with each occurrence of a name in the that-clause of an ascription: not only the mode of presentation that is ascribed to the believer, but also the one semantically exercised by the speaker, which the hearer must share to correctly understand the ascription. To remedy this, Récanati adapts a proposal of Quine's which increases the number of 'positions' in the truth-conditionallyrelevant part of the proposition expressed by the ascription as a whole that might be associated with modes of presentation, making the required room for both exercised and ascribed modes of presentation, at the cost of moving to a triadic analysis.

I will start by trying to show that Récanati is mistaken about the relevance of what he calls semantically exercised modes of presentation to the issue of the structure of the truth-conditionally- relevant parts of the proposition expressed by an ascription of belief - that is, to the issue of what sort of fact is claimed to hold in a belief ascription. But I think that this mistake is merely a distraction -indeed, that it leads to an unnecessary retreat from what is a plausible and interesting proposal about the semantics of belief 
sentences: the dyadic analysis. I then will assess the advantages of that plausible proposal over the analysis that John Perry and I have defended. I will conclude with a brief and very speculative exploration of one way of viewing our practices of attitude ascription on which a number of apparently conflicting views on the issueincluding those of Kripke, Salmon, and Soames, as well as Récanati and Perry and myself--might all be seen as importantly correct.

Récanati is surely right that, to understand a statement, a hearer needs to know more than its truth-conditional content, if truth-conditional content is assigned in such a way that the truthconditional content of the sentence 'Cicero was louder than Tully' is the singular proposition (3). What Récanati says here and elsewhere (Récanati 1993) suggests that he takes such singular propositions to correctly portray truth-conditional content. He believes, however, that there is more to semantic content than mere truth conditional content - there is also the matter of what modes of presentation of the elements of that truth-conditional content are required for proper understanding of the utterance: there are semantically exercised modes of presentation. I will not dispute here this contention about semantics, though I am not confident of the adequacy of any ordinary concept of understanding an utterance to ground a clear and useful notion of content in this way.

But why does Récanati raise the issue of the non-truth-conditional content of statements in a discussion of the truth-conditional content of belief ascriptions? Since, on the dyadic analysis, a quasi-singular proposition is referred to by the that-clause in an ascription so as to be ascribed to the agent, then it seems on the face of it that the entire ascribed quasi-singular proposition-modes of presentation and allis truth-conditionally relevant. After all, the truth of the ascription depends on whether the believer believes that quasi-singular proposition, and this requires thinking of its constituents in the ways given by the associated modes of presentation. Hence, the ascribed modes of presentation ought to be counted as truth-conditionally relevant constituents of the semantic content of the entire ascription, on a par with the referent of a name, rather than as truth-conditionally irrelevant bits of the content of the ascription, on a par with a mode of presentation under which the hearer must, for correct understanding, think of the referent of a name. 
So why does Récanati seem to take the modes of presentation required for understanding the ascription to be relevant to the truthconditional content of the ascription? One reason to do so would derive from thinking that what normally is truth-conditionally irrelevant content 'rises to the occasion' and becomes part also of truth-conditional content in belief ascriptions. Early on in his contribution, it may seem that this is what he has in mind, since he seems to want to defend the dyadic account as 'semantically innocent' by showing that what a that-clause refers to, according to the account, is just the quasi-singular proposition that the embedded sentence would express in isolation. But Récanati seems to give up on this idea, because he recognizes that the mode of presentation of a thing that is exercised by the speaker in connection with a name in the that-clause is not in general the one that is ascribed to the believer. But still Récanati worries that considerations about exercised modes of presentation show the dyadic account to be unsatisfactory. Récanati thinks that there is no room in the dyadic account for the distinction between exercised and ascribed modes of presentation -no way to distinguish the modes of presentation that the hearer is meant to employ from those that the believer is claimed to employ. After all, in a quasi-singular proposition there is room only for one mode of presentation to be associated with a thing. To make room for both exercised and ascribed modes of presentation, Récanati borrows Quine's device and moves to a triadic analysis (of which I will not provide the details).

But there is no need for the retreat from the dyadic account. If the truth-conditional content of a belief ascription includes as a constituent a quasi-singular proposition, which has as constituents an individual and an associated mode of presentation, there are so far no consequences whatever for the question of how the hearer must, to understand the ascription, think about that individual-for this latter is a question about non-truth-conditional content. If the speaker of 'John believes that Cicero was loud' is referring to a quasi-singular proposition, providing it as a constituent of the fact she is claiming to hold, as opposed to merely expressing it, then she is therein referring (in a relevant sense) both to Cicero and to a mode of presentation of him. Since both of these are truth-conditionally relevant bits of semantic content, on Récanati's view there are (or at least may well be) modes of presentation of them that are exercised 
and 'conveyed' as part of the quasi-singular proposition expressed by the entire ascription. So there is already room in the dyadic account for the distinction between exercised and ascribed modes of presentation, given that the ascribed quasi-singular proposition is part of the truth-conditional content of the ascription. To see this clearly, consider the following graphical representation of the full semantic content, on the dyadic analysis, of the ascription 'Tom believes that Cicero was louder than Tully', in which elements that are truth-conditionally relevant are carefully separated (below the dotted line) from those that are not (which are above the line). The modes of presentation $m_{1}$ and $m_{2}$ are the ascribed modes of presentation: they are parts of the quasi-singular proposition that is the second argument of the relation-instance that is claimed to hold in the ascription, and so they are truth-conditionally relevant bits of the content of the ascription (this is entirely consistent with their being truth-conditionally irrelevant parts of the ascribed quasisingular proposition). The modes of presentation $m_{3}, m_{4}$, and $m_{5}$ are those the hearer is meant to employ in understanding the ascription. The important point is that there is no modification of the dyadic view here, but only a careful employment of it. ${ }^{1}$

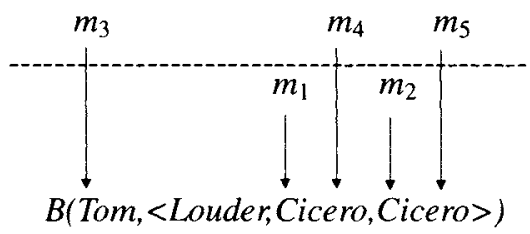

1 Note that there is also 'room' in the dyadic account for exercised modes-of-presentation of the ascribed modes-of-presentation-for the way the hearer must, to understand the ascription, think of the ascribed modes of presentation. Depending on one's views about the varieties of modes of presentation we ascribe in such statements, this may be very useful. For it may turn out that modes of presentation, like other truth-conditionally relevant bits of content, can be misrecognized; if so, understanding a belief ascription might involve thinking about the relevant mode of presentation in a certain intended way. For instance, suppose that Kripke (1979) was misled about Pierre, who in fact has but one mode-of-presentation of London. Then, perhaps Kripke unwittingly expresses the same truth-conditional content with the sentences, 'Pierre believes that London is pretty' and 'Pierre believes that Londres is pretty'. Both sentences, it might be held, ascribe the same mode of presentation of London, which both is the mode of presentation that Pierre formed early on in France, and is the mode of presentation that he uses today in his thinking about his home town. Still, we can distinguish between two ways of thinking of that mode of presentation that Kripke and his readers employ, and that Kripke exercises (in Récanati's sense) in the two ascriptions. 
I have been explaining why I think that Récanati is mistaken about the need to abandon the straightforward dyadic analysis. But even granting that there is such a need, I find it unclear why Récanati abandons the dyadic account of the belief relation itself. Rather than do that, he could treat the name 'Cicero', in his example, as having wide scope over the attitude verb, with a tacit variable (or variable-like slot) anaphoric on it within the logical scope of the verb. I can see no reason at all in Récanati's discussion to provide another argument in the belief relation itself.

In any case, if I am right that Quine's device is unnecessary, then we face the prospect of an unsullied dyadic account that lives up to the advance billing. Let me describe that account again, so that I can highlight certain of its aspects. The view is that a typical belief ascription expresses (as its truth-conditional content) a relation between a person and a quasi-singular proposition, where the latter is the truth-conditionally-relevant part of the semantic content of the that-clause (or, as I shall say for short, the that-clause's truthconditional contribution, or sometimes, just its content; it is what the that-clause refers to, as Récanati puts it). The modes of presentation in the ascribed quasi-singular proposition are not the truthconditional contributions of any syntactic expressions, though they are parts of the truth-conditional contribution of the that-clause. Thus, they are, in John Perry's phrase (Perry 1986), unarticulated constituents of the truth-conditional content of the ascription. (An unarticulated constituent of truth-conditional content can be part of the content of a complex expression (e.g., a sentence or a complex predicate phrase), so long as it is neither contributed to the content of the complex expression by being the content of a component expression, nor assembled from any such articulated contents. For instance, the unarticulated location allegedly experiencing rain is a component of the content of the first conjunct in 'It's raining and I'm hungry'.)

The account of belief ascribing in contrast with which Récanati sketches his view is one developed by Perry and me (Crimmins and Perry 1989, Crimmins 1992), which shares certain important features with an earlier account of Schiffer's (1977). (I do not like calling Perry's and my account a 'hidden indexical analysis', because for one thing, there is no expression posited in the analysis to be hidden or indexical, and for another, the context-sensitivity in 
question is very unlike the indexicality typified by 'I' and 'today'.) According to Perry's and my account, the ascribed modes of presentation are not parts of the content of the that-clause (for we take the content of a that-clause to be a singular proposition); indeed the ascribed modes of presentation are not held to be parts of the content of any unit smaller than the entire ascription (we do not consider the question of the content of the predicate phrase). Aside from that difference, Perry's and my account is really not so very different from Récanati's. As in Récanati's account, the ascribed modes of presentation are taken to be unarticulated constituents of the truth-conditional content of the ascription. And, as in Récanati's account, for the ascription to be true is for the believer to have a belief whose truth-conditional content is given by a singular proposition, and which involves the ascribed modes of presentation in the proper way.

Récanati's account (by which I mean the dyadic account) has definite advantages over Perry's and mine. Récanati is certainly right that a dyadic account vindicates an intuition of dyadic structure. A belief ascription seems to divide into three parts: the part that specifies the believer, the part that indicates that it is believing that is alleged, and the part that specifies what is alleged to be believed. I doubt that this in itself is much of a recommendation of a dyadic account, since plenty of plausible truth-conditional analyses violate equally strong intuitions of logical form (witness Davidsonian event analyses of various locutions, analyses of subjunctive conditionals that bring in one or another unarticulated parameter, analyses of perspectival locutions that bring in perspectives, and so on). Récanati himself is quick enough to abandon a dyadic account when it looks like Quine's move might help provide needed flexibility. But there is a serious issue here inasmuch as a dyadic account is able to make easy sense of the many locutions in which the things people believe (where these 'things' seem to be individuated more finely than by truth-conditional content) are quantified over, identified, distinguished, and in general treated to all appearances as things. Récanati's account indeed has things aspiring to this role (I will leave aside the question whether they can perform the role satisfactorily), whereas on Perry's and my account, no appropriate things are easily to be found (singular propositions are too coarse). 
On the other side of the scales, Perry's and my account has a number of advantages over Récanati's. For one, it takes 'that-clauses' always to provide, as their contributions to truthconditional content, singular propositions (on Récanati's account, sometimes they provide singular propositions, sometimes quasisingular ones). Surely this is some sort of advantage-maybe it seems a weightier one if we consider that this amounts to respecting the apparent grammatical form of the that-clause itself - but I won't dwell on this. A second advantage is that Perry's and my analysis seems more naturally extended to account for opaque contexts in reports of 'objectual attitudes', as perhaps occur in 'Tom admires Cicero [but not Tully]', and 'Lois pitied Clark [but not Superman]' Perry and I can hold with some plausibility that modes of presentation enter here as unarticulated constituents of truthconditional content that are not parts of the objects of the attitudes ascribed to the agents. Recall that Récanati cushions the introduction of his use of quasi-singular propositions by noting that they are just like singular propositions, except that the individuals are 'associated' with modes of presentation. However palatable that may be, I doubt that we would be happy to admit of a 'quasi-person' just like the person Cicero, except associated with a mode of presentation. If we are glad to abandon the apparent dyadic form in an analysis of opaque objectual attitudes (which seem dyadic on the surface), why balk at what is essentially the same move in the case of propositional attitudes? Last and least, I think there may be some attraction to taking our talk to concern singular propositions rather than quasi-singular ones, to the extent (if any!) to which singular propositions are the more metaphysically natural creatures, at least on our conceptual scheme. Singular propositions might answer to, or flow from, the somewhat intuitive notions of states-of-affairs or of property-instances and relation-instances (this is obscured by thinking of them as sequences or as set-theoretic constructs rather than as structured abstract entities of a unique kind). Quasi-singular propositions in contrast seem like odd creatures. But this does not strike me yet as a very forceful concern, since it might be met by taking quasi-singular propositions to be something like thought-types, which build in not only what (truth-conditionally) is thought about but also how it is thought about. This seems natural enough, though I think, admittedly for idiosyncratic reasons, that 
the particular 'how' information that we actually convey in many belief ascriptions might make this far less natural when its consequences are spelled out (the 'how' we ascribe, I think, often is not very 'what-ish', and so may be out of place in a natural conception of thought-types construed as the objects of belief).

If we are to weigh advantage and disadvantage now (and I am quite sure that not all the relevant considerations are yet before us), perhaps Récanati's dyadic account will win the day over Perry's and mine. No regrets: I would be quite happy if the correct account were to turn out to be as close as that to one that I have defended.

But in the space remaining to me I want to venture out a bit from the security of our near-agreement, and to engage in wild speculation of a sort that I hope will be provocative, but that is likely to turn out to have been completely misguided.

I wonder if there might be an account of belief ascribing on which not only Récanati and Perry and I, but also Nathan Salmon and Scott Soames and Saul Kripke, among others, all turn out, nearly enough, to be right. Salmon (1986) and Soames (1987), notoriously, hold that belief ascriptions simply attribute a relation of belief between persons and singular propositions (no distinctions are made between modes of presentation). Saul Kripke (1979) proposes that in some such puzzling cases our practices of ascribing beliefs might simply 'break down'. Récanati and Perry and I take ascriptions to report facts of a fairly sophisticated sort involving modes of presentation.

Consider some strange things that we find natural to say and very easy to interpret:

(4) Hesperus was more highly regarded than Phosphorus.

(5) Hammurabi's beliefs about Hesperus were more accurate than his beliefs about Phosphorus.

(6) Hammurabi, not a morning person, saw Hesperus more often than he did Phosphorus.

(7) Hammurabi would wax poetic about two celestial bodies, namely Hesperus and Phosphorus.

Such talk often is dismissed as 'loose'. It is loose, I think-we are not (most of us) willing to stand behind it as perspicuously expressing what we mean; so it is aptly dismissed. But perhaps this loose talk is revealing of how attitude ascriptions work. One way of 
making sense of the talk is to take it to involve a very shallow pretence that there is not only one individual here, but two, Hesperus and Phosphorus (I have described the content of the pretence itself loosely, but also naturally, no?). The connection to belief ascription is this: when we talk of beliefs about Hesperus as contrasted with Phosphorus (knowing that they are identical), perhaps we are shallowly pretending, for the purposes of characterizing mental states, that Hesperus and Phosphorus are different individuals.

I will take a first run at the account that $I$ have in mind by telling one of those 'analytic-genetic' stories. We start with the idea that our ascribing practices are built around a certain mistaken conception of thought: a conception on which belief itself just is a relation to singular propositions, unmediated by modes of presentation. The mistake is the assumption that we have transparent, unmistakable cognitive grasps on ordinary individuals, properties, and relations, and hence on ordinary singular propositions. On this conception, there cannot be two beliefs with distinct cognitive significance that have as their truth conditional contents the same singular proposition, because there is no such thing as different modes of presentation of the things we think about. Imagine yourself blithely assuming that it just cannot happen that someone believes that $X$ has some property while they do not believe that $Y$ has it, when really $\mathrm{X}$ and $\mathrm{Y}$ are the same individual (is it so very hard to imagine unreflectively assuming this?). You and your like-minded comrades design a marvellously perspicuous technique for ascribing belief: you use a that-clause which has as its truth-conditional content the singular proposition you wish to ascribe to the believer. Quantifying in and substitution of coreferential names are seen as completely unproblematic. It then comes as an annoying surprise to find that, on your strictest standards of ascribing beliefs, you find yourself wanting to say things that are clearly false or even impossible on your conception of believing ('Lois believes that Superman can fly, but she does not believe that (lark Kent can fly'); and you come to a hazy recognition that this is because we do not in fact have transparent grasps on individuals and on singular propositions. But you do not abandon the essentials of your belief-ascribing practices, even though, as Kripke holds, these practices have in some sense broken down. Instead of starting from scratch, you force the tidy old practice into duty for which it was not designed. You allow yourself 
to say things like 'Lois believes that Superman is stronger than Clark', but on your newly enlightened view, what now makes it okay to say that about Lois is a fact that is more complicated than simply a relation to a singular proposition-it is a fact that involves modes of presentation. But the idea that belief is just a relation to singular propositions has become fossilized in grammar. You have given up thinking that belief really relates us transparently to singular propositions, but you continue to talk as though it does. I will explain soon in some detail what it means to talk as though it does. In brief, it involves, when ascribing a belief, making as if simply to ascribe a singular proposition; it involves a certain sort of pretence. In any case, fortunately you and your comrades normally find it clear enough what you are trying to say without your settling on some metaphysically apt but more complicated way of talking. So you do not find a different way of talking, and eventually your stop-gap practices of pretending become conventionally sanctioned as ways of saying (and in general of semantically expressing) - in a not-soperspicuous way-the complicated claims you are getting at.

Leaving the analytic-genetic story behind, let me try to outline the main points of the resulting picture of our ascribing practices. There is a sense in which the grammar of our practices (by which I mean something like their 'surface logical structure') is designed to ascribe singular propositions as the objects of our attitudes-it is designed not to make distinctions among modes of presentation. We do not treat this grammatical feature of the practice seriously, however. We do not, that is, really believe that we can say what we want to say about beliefs merely by ascribing singular propositions to the agent. So the use of this practice involves (at least at times) one or another kind of transparent, conspiratorial pretence-always some pretence such that the truth conditions of what we really want to say are identical with the conditions under which our pretended ascription of a singular proposition is true on the pretence. I will be more specific in a moment. So we adopt the pretence, and we therein speak as if we are using the ultra-naive practice. Understanding our actual practice involves latching on to this as a guiding principle. Such theorists as Salmon and Soames, then, may well be right about what we make as if to say in an attitude ascription: what we pretend to say involves ascribing a singular proposition while making no discrimination among modes of presentation. 
Now, this does not entail that in ascribing a belief one really literally only ascribes a singular proposition. One obstacle to such an entailment would stem from the fact, if it is one, that what we literally say has some tight connection to what we standardly and systematically mean by sentences like the one that we use (though I would not want in this case to rest with just that sort of general argument). In any case, there is at least the possibility that what we really say, in such cases, differs systematically from the picture given by the grammar of the practice (which reflects rather what we pretend to say), and it is this possibility that I want to pursue.

To make clearer the sort of thing I have in mind, I will be more specific than I have any confidence in being about just what we make as if to say in attitude reports, and how that determines what we really do say. First let's consider cases in which misrecognition is not a live possibility. Suppose I say, in a discussion of international affairs,

(8) Saddam believes that Clinton is timid.

Even though there is no hint of multiple modes of presentation in this case, I think that not just any mode of presentation of the person Clinton that Saddam might have would be relevant to the truth of the ascription: Saddam might recall having seen some timid person (Clinton) briefly in an elevator many years ago in Spain; but that would not make my ascription true. Only modes of presentation of Clinton of a certain sort are relevant: call such modes of presentation 'normal-Clinton-concepts' (what it takes for a mode of presentation to be one I will not say, but will assume settled). Then, I think the pretence that we share in the conversation is roughly this:

(9) Let's pretend, for the purposes of characterizing thoughts about Clinton, that there is but one way to think of him, namely, with a normal-Clinton-concept.

With this pretence in force, we can talk neatly of thoughts 'about Clinton', as a way of characterizing thoughts that we might more perspicuously characterize, but only by laboriously speaking of thoughts 'about Clinton under a normal-Clinton-concept'. When I say 'Saddam believes that Clinton is timid', employing this pretence, I make as if to ascribe to Saddam belief simply in the singular proposition attributing the property of timidity to the person Clinton. For my ascription to be true on the pretence is for 
Saddam (really) to have a belief with that singular proposition as its truth-conditional content and involving a normal-Clintonconcept in the proper way.

The more interesting cases are those in which there is at least a hint of the possibility of misrecognition-of multiple, nonidentified modes of presentation of the same individual. As I have said, I think that we might portray speakers and hearers of attitude ascriptions in many such cases as conspiratorially pretending that there are two individuals where really there is just one: that Cicero and Tully, or London and Londres, or Hesperus and Phosphorus, or Superman and Clark Kent, are distinct. We pretend to refer to the pretended entities in belief ascriptions. Again, the idea is that we do this because it is the most convenient way, and the standard one, of adapting the unsatisfactory practice of characterizing thoughts simply by what's thought about, to this sort of case. We can use that practice fairly smoothly so long as we pretend that there are different individuals to talk about, and hence different singular propositions to ascribe. Consider the following ascription:

(10) Hammurabi believed that Hesperus was visible in the evening.

The nature of the pretence involved here might be very roughly characterized as the pretence that Hesperus is distinct from Phosphorus. A bit less roughly, it might be delimited as follows:

(11) Let's pretend, for the purposes of describing thoughts involving one or both of two modes of presentation of Venus, namely 'Hesperus-concepts' and 'Phosphorus-concepts', that there are two celestial bodies thus thought of, which we can call 'Hesperus' and 'Phosphorus'.

The pretence links the pretend bodies to the real modes of presentation that we want to distinguish in characterizing thoughts. Given this, the real-world contribution to what makes it true on the pretence that Hammurabi believed that Hesperus was visible in the evening, is exactly the fact that he really believed of Venus, with his 'Hesperus-concept', that it was visible in the evening. Here, as in the Saddam/Clinton case, the real fact required to make the pretend-statement true on the pretence, is just what Récanati and I are advancing as the truth-conditional content of the belief ascription. Since it is this content that speakers of such sentences in such cases standardly and systematically mean by them, and in 
some sense conceive of their ascriptions as saying, then perhaps we can mount some argument to viewing it as the genuine truthconditional content of belief ascriptions. ${ }^{2}$

I will end by returning briefly, and surely unsatisfactorily, to the particular issue dividing Récanati's account from Perry's and mine: the question whether the contribution of the that-clause to the truthconditional content of an ascription does or does not involve the ascribed modes of presentation. If my wild speculations are not too far from the truth, then there is a simple reason that Récanati's view matches grammatical form (at the level of the whole ascription, at least) more closely than Perry's and mine. Take the Hammurabi/ Hesperus case we have just been considering. Given the nature of the pretence involved in the case, the that-clause 'that Hesperus was visible in the evening' is semantically tied to the mode of presentation that really is being ascribed. That is, it is the pretended truth-conditional content of the that-clause that determines which mode of presentation is (really, seriously) ascribed. That is why belief ascriptions behave grammatically as though the that-clauses 'carry with them' the ascribed modes of presentation. And Récanati's account honours this grammatical feature, leading to the advantages that I mentioned above. But the advantages which I have claimed for Perry's and my account remain. It might turn out, I suppose, that what separates Récanati from Perry and me is a question that has no answer, if, as the wild speculations might suggest, there is little reason to take belief ascriptions to express perspicuously what we use them to say. ${ }^{3}$

2 I am sure there are lots of difficulties with these ideas about pretence that I have not even begun to see. Let me record just one that I have begun to see (thanks to Steve Yablo): the situation in which someone who herself takes Hesperus and Phosphorus to be distinct reports of Hammurabi that he believes that Hesperus is brighter than Phosphorus is not easily handled on the model of either of the two cases I have presented. Such cases raise fascinating issues about pretence and presupposition, and I am somewhere between hoping and believing that they can be accommodated in the general picture that 1 have been sketching. Let me also record my debt to Kendall Walton's serious explorations of the notion of pretence, and especially to his discussion of non-existence claims in Walton (1990). The present account suggests treatments not only of the loose talk mentioned earlier, but also of ascriptions of attitudes 'about non-existent objects', and the like. I hope to expand on this account elsewhere, perhaps in a more general discussion of what I call 'semantic pretence'.

3 Thanks to Jim Joyce, Ken Walton, and Steve Yablo for valuable suggestions. 


\section{REFERENCES}

Crimmins, M. 1992. Talk About Beliefs. Cambridge Ma.: MIT Press.

Crimmins, M., and J. Perry. 1989. 'The Prince and the Phone Booth: Reporting Puzzling Beliefs.' Journal of Philosophy 86:685-711.

Kripke, S.A. 1979. 'A Puzzle About Belief.' In A. Margalit (ed.), Meaning and Use, 239-283. Dordrecht: Reidel.

Perry, J. 1986. 'Thought Without Representation.' Proceedings of the Aristotelian Society Supplementary Volume 60:263-283.

Récanati, F. 1993. Direct Reference. Oxford: Basil Blackwell.

Salmon, N. 1986. Frege's Puzzle. Cambridge Ma.: MIT Press.

Schiffer, S. 1977. 'Naming and Knowing.' In P. French, T. Uehling, and H. Wettstein (eds.), Midwest Studies in Philosophy, Vol. 2, 28-41. Minneapolis: University of Minnesota Press.

Soames, S. 1987. 'Direct Reference, Propositional Attitudes and Semantic Content.' Philosophical Topics 15:44-87.

Walton, K. 1990. Mimesis as Make-Believe. Cambridge Ma.: Harvard University Press. 